\title{
Can Whitnall's tubercle be localized using palpable landmarks around the orbit?
}

\author{
Ali Can Korkmaz ${ }^{1}$ (D), Necati Salman ${ }^{1}$ (D), Aysun Uz ${ }^{1,2}$ (D) \\ ${ }^{1}$ Department of Anatomy, Ankara University School of Medicine, Ankara, Turkey \\ ${ }^{2}$ Department of Neuroscience, Ankara University Graduate School of Health Science, Ankara, Turkey
}

\begin{abstract}
Objectives: Whitnall's tubercle (WT) is located deep in the lateral canthus and on the lateral orbital wall and has crucial structures attach to it. We aimed to define the location of WT using the palpable bone landmarks which can be used as reliable landmarks in eyelid and orbital surgery to prevent the damage of stuctures associated with WT.

Methods: Forty-four adult skulls (22 right, 22 left) were included to the study. The skulls were divided into two groups according to the apparancy of the WT. The distances from WT to the frontozygomatic suture, the marginal tubercle, the anterior point of the zygomatic arch, and the lateral margin of the orbit were measured. The clock positions of WT according to the marginal tubercle and the anterior point of the zygomatic arc were determined.

Results: The distances of the WT to the marginal tubercle, the anterior point of the zygomatic arch, the lateral margin of the orbit, and the frontozygomatic suture were $9.92 \pm 1.65 \mathrm{~mm}, 16.48 \pm 1.86 \mathrm{~mm}, 2.32 \pm 0.53 \mathrm{~mm}$ and $9.66 \pm 1.44 \mathrm{~mm}$, respectively. WT was at 8 and 9 o'clock positions on the left, and at 4, 3, and 2 o'clock positions on the right according to the marginal tubercle. WT was at 10 o'clock position on the left, and 2 and 1 o'clock positions on the right according to the anterior point of the zygomatic arch.

Conclusion: The marginal tubercle, the lateral margin of the orbit, and the anterior point of the zygomatic arch can be used as standart bony landmarks in eyelid and orbital surgery to prevent the soft tissue damage relevant to WT. The high kappa values of the interclass and intraclass correlations suggest that these parameters are reliable and repeatable for clinical use. Out of these parameters, the anterior point of the zygomatic arch is more beneficial to locate the WT because of the standard clock positions. The WT is typically located at 10 o'clock position on the left and 2 o'clock position on the right according to the anterior point of the zygomatic arch.
\end{abstract}

Keywords: lateral canthus; marginal tubercle; orbita; Whitnall's tubercle; zygomatic arch

Anatomy 2021;15(2):121-126 C2021 Turkish Society of Anatomy and Clinical Anatomy (TSACA)

\section{Introduction}

Whitnall's tubercle (WT) was first described as a bony prominence located on the lateral orbital wall by Samuel Ernest Whitnall in 1911. He indicated that this tubercle was about $11 \mathrm{~mm}$ below the frontozygomatic suture and a few millimeters deep to the lateral margin of orbit. ${ }^{[1]}$ Other terms used for WT are; lateral orbital tubercle, ${ }^{[2-7]}$ lateral palpebral tubercle, ${ }^{[8]}$ orbital eminence, ${ }^{[8,9]}$ and orbital tubercle. . $3,5,7,8,10-13]^{-10}$

The clinical importance of the WT comes from the anatomical structures attached to it. These structures are the check ligament of lateral rectus, aponeurosis of leva- tor palpebrae superioris, suspensory ligament of the eyeball (Lockwood's ligament), and lateral palpebral or tarsal ligament (raphe palpebralis lateralis) which also participate in the lateral retinaculum. ${ }^{[1]}$ Other anatomical structures participating in the lateral retinaculum are the Whitnall's ligament, intermuscular transverse ligament, and orbital septum. ${ }^{[8,14,15]}$ The anatomy of this tubercle is essential to protect the soft tissue structures attached to or adjacent to the WT in orbital and eyelid surgeries such as lateral canthopexy, ${ }^{[15]}$ lateral canthotomy, ${ }^{[16]}$ lateral orbitotomy, ${ }^{[17]}$ and blepharoplasty. ${ }^{[6,18]}$

The lateral palpebral ligament consists of two parts, superficial and deep. The superficial part contributes to 
the orbital septum. ${ }^{[1]}$ However, the deep part participates in the lateral retinaculum and attaches to the WT. ${ }^{[1]}$ The signs of aging are due to the weakening of the lateral retinaculum elements' elastic fibers. These are noticed in the lower and upper eyelids. In healthy individuals, elastic fibers weaken with aging, but the lower eyelid length has not increased. ${ }^{[19]}$ Due to this pathophysiology mechanism, the lateral retinaculum and WT are crucial in eyelid surgeries. ${ }^{[6,15,16,18]}$

Another critical aspect of WT is exotropic Duane syndrome. In this situation, the lateral rectus is released from the WT, where the check ligament of this muscle is attached and then sutured to the lateral canthal tendon. ${ }^{[20]}$

In this study, we aimed to locate the WT using palpable bony structures close to the WT. We determined these bony structures as the marginal tubercle, the lateral margin of the orbit, the anterior point of the zygomatic arch, and the frontozygomatic suture. Since the WT location could not be determined by inspection, we think our study will be valuable for the preparation phase of surgical access.

\section{Materials and Methods}

A total of 30 skulls (60 orbits) taken from the bone collection of Department of Anatomy, Ankara University School of Medicine were included to the study.
However, 8 of the skulls had orbits with impaired bone integrity or had pathological deformation, so they were excluded from the study. Thus, the measurements were carried out on 44 orbits bilaterally (22 left and 22 right). The age and gender of these orbits were not certain. WT was determined on the lateral wall of the orbit. After that, we divided orbits into two groups according to the appearance of WT (Figure 1). If WT was visible, it was considered as "apparent". If it was only determined by palpation, it was regarded as "non-apparent". Skulls were positioned and fixed on the Frankfort horizontal plane to determine the anatomical position of the WT deep within the lateral orbital wall. The shortest distances of WT to the marginal tubercle, the lateral margin of the orbit, the anterior point of the zygomatic arch, and the frontozygomatic suture were measured directly on the skulls using vernier caliper $(0.01 \mathrm{~mm}$ resolution). The position of the WT was noted taking the marginal tubercle and the anterior point of the zygomatic arch as landmarks for to use a clock method (Figures 2 and 3 ).

Two observers (ACK and NS) measured all parameters three times. The first measurement was performed by only one observer (ACK). The second and third measurements were performed by another observer (NS). Descriptive statistics (mean and standard deviation) of the measurements were calculated with all three measurements. Interclass (ACK-NS) and intraclass (NSNS) correlations were examined with the distances meas-
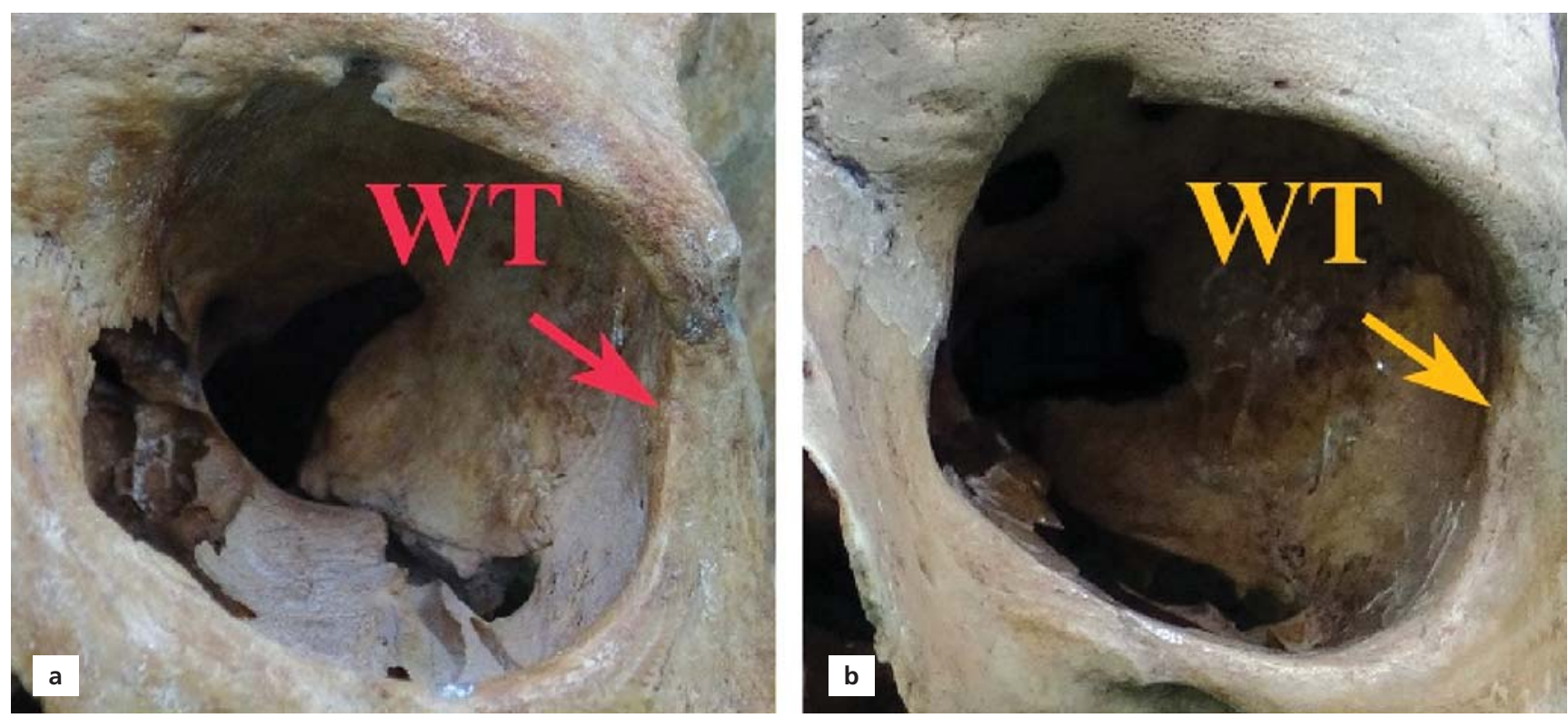

Figure 1. Whitnall's tubercle on the lateral orbital wall (anterior view). (a) Non-apparent Whitnall's tubercle; (b) apparent Whitnall's tubercle. WT: Whitnall's tubercle. 


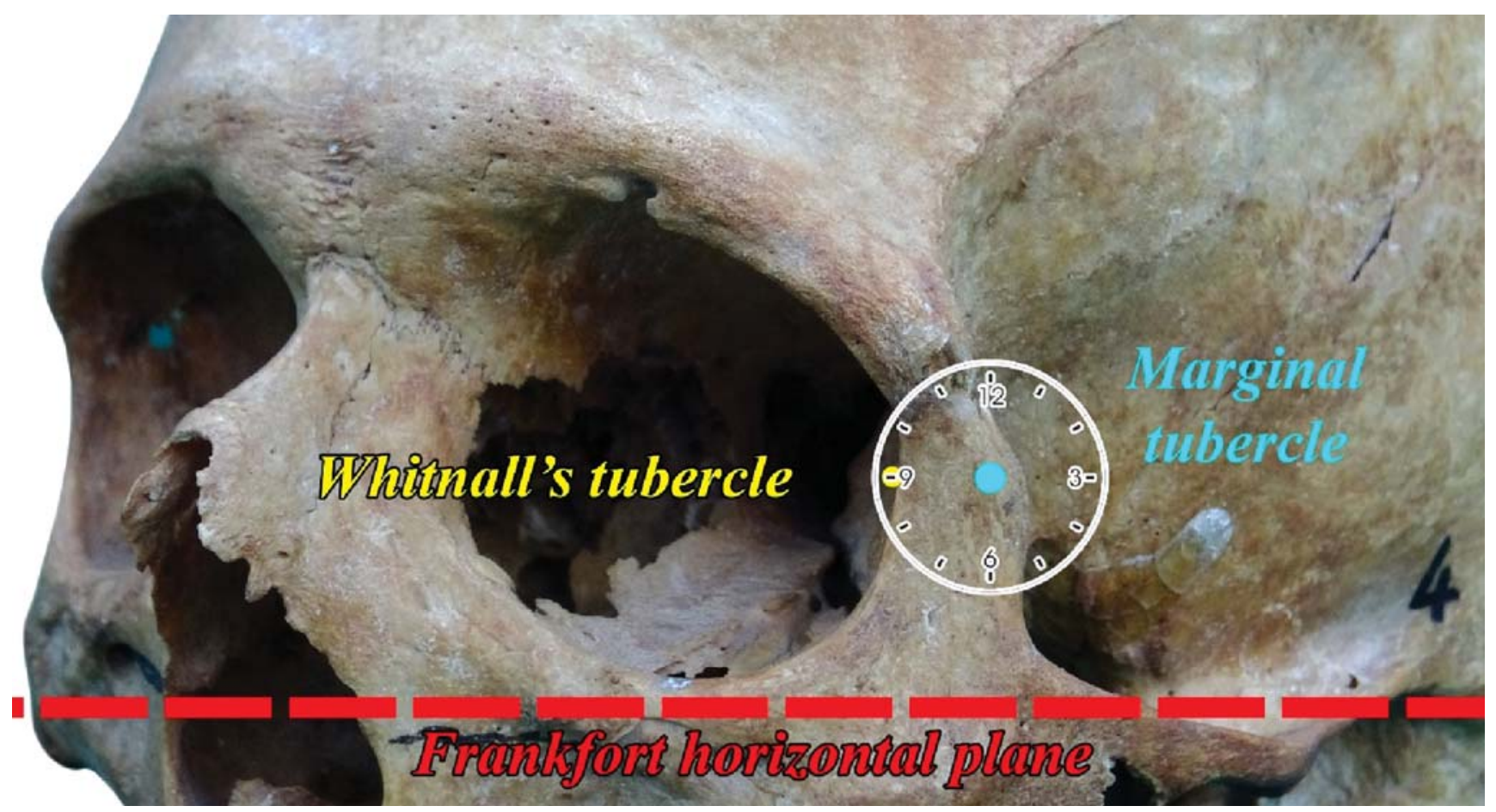

Figure 2. Clock position of the Whitnall's tubercle (yellow point) according to the marginal tubercle (blue point).

ured three times. An independent sample t-test was used to determine whether there was a significant difference between right and left sides, and between apparent and non-apparent WTs. The statistical analyses were performed with Statistical Package for Social Sciences (SPSS Version 20, Armonk; NY, USA).

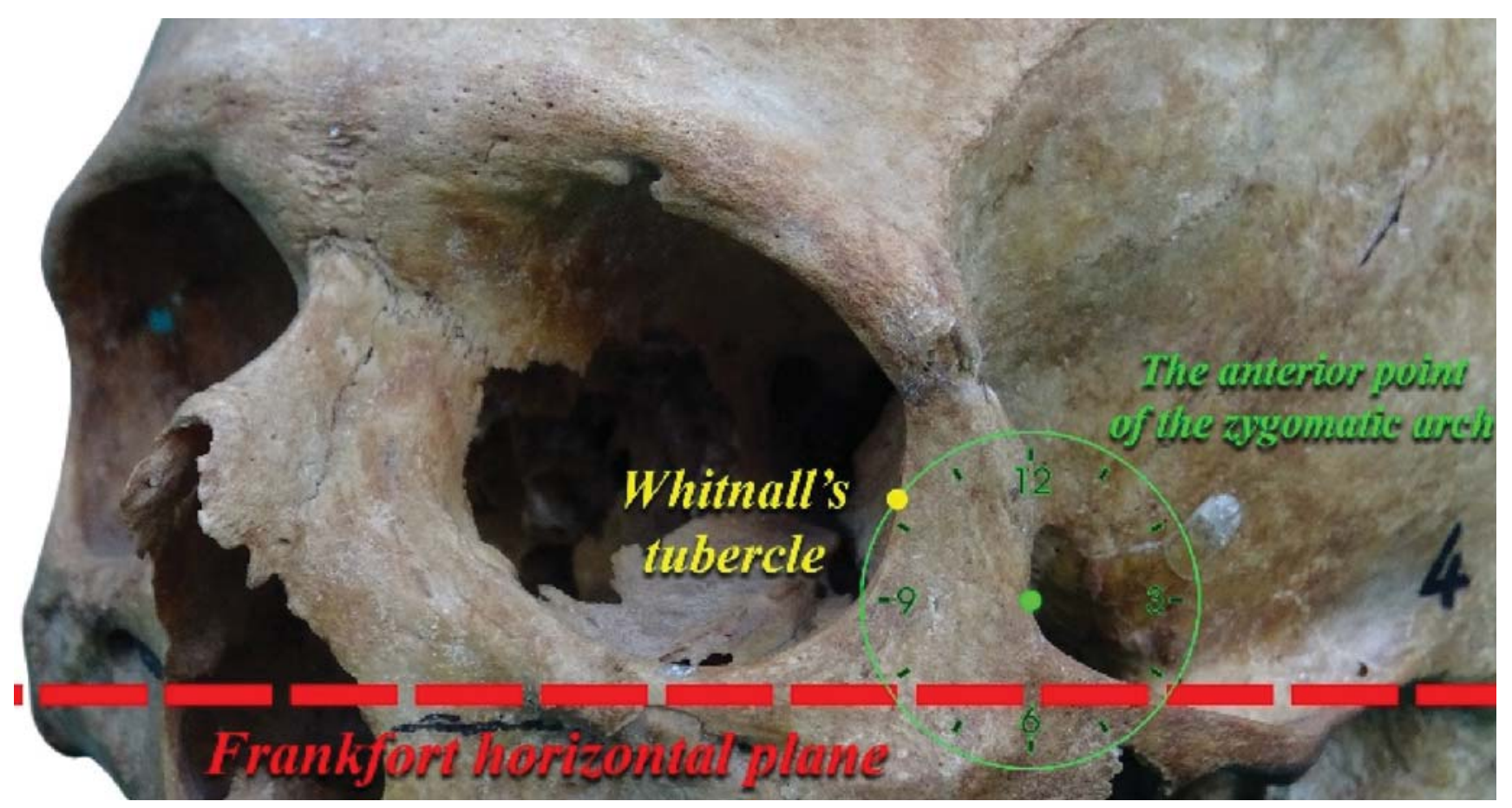

Figure 3. Clock position of the Whitnall's tubercle (yellow point) according to the marginal tubercle (blue point). 
Table 1

The topographical measurements of Whitnall's tubercle.

\begin{tabular}{|c|c|c|c|c|c|}
\hline Parameters & Right (mm) & Left (mm) & Apparent WT (mm) & Non-apparent WT (mm) & Total (mm) \\
\hline WT-marginal tubercle & $9.91 \pm 1.38$ & $9.94 \pm 1.89$ & $10.02 \pm 1.42$ & $9.64 \pm 2.2$ & $9.92 \pm 1.65$ \\
\hline WT-anterior point of the zygomatic arch & $16.92 \pm 1.94$ & $16.04 \pm 1.69$ & $16.55 \pm 1.94$ & $16.27 \pm 1.62$ & $16.48 \pm 1.86$ \\
\hline WT-lateral margin of orbit & $2.36 \pm 0.52$ & $2.27 \pm 0.54$ & $2.35 \pm 0.54$ & $2.22 \pm 0.5$ & $2.32 \pm 0.53$ \\
\hline WT-frontozygomatic suture & $9.41 \pm 1.46$ & $9.91 \pm 1.39$ & $9.53 \pm 1.25$ & $10.04 \pm 1.88$ & $9.66 \pm 1.44$ \\
\hline
\end{tabular}

WT: Whitnall's tubercle.

\section{Results}

Out of 44 orbits (22 right, 22 left), WT was apparent in 33 orbits (75\%) and non-apparent in 11 orbits (25\%). Sixteen of apparent WTs were on the right side; 17 apparent WT were on the left side (Table 1). There was no significant difference between the parameters whether the WT was apparent or not, and whether it was on the right or left side.

Our measurements defining the WT clock position concerning the anterior point of the zygomatic arch and marginal tubercle were demonstrated in Table 2 and 3. According to the marginal tubercle, WT was at 8 o'clock (13 orbits) and 9 o'clock (9 orbits) positions on the left side and it was at 4 o'clock (15 orbits), 3 o'clock (6 orbits), and 2 o'clock (1 orbit) positions on the right side. According to the anterior point of the zygomatic arch, WT was located at 10 o'clock position on the left side and at 2 o'clock (20 orbits) and 1 o'clock (2 orbits) positions on the right side.

The kappa values of the interclass and intraclass correlations were demonstrated in Table 4 . The values between 0.61 and 0.8 in Table 4 indicated a strong correlation. The values between 0.81 and 1 in Table 4 showed an almost perfect correlation.

\section{Discussion}

Recent studies showed that WT is not always present. This tubercle was noticed at a rate of $95 \%$ by Whitnall, ${ }^{[1]}$ $63 \%$ by Buschkowitsch, ${ }^{[13]} 80.1 \%$ by Kangas, ${ }^{[12]} 80 \%$ by Ono ${ }^{[11]} 49.15 \%$ by Tomita, ${ }^{[2]]} 96.3 \%$ by Didio, ${ }^{[9]}$ and $70 \%$ by Fries at al. ${ }^{[8]}$ The most crucial reason why it is seen at different rates is the differences between populations. Another important reason is how the existence of tubercle is decided in these studies. Buschkowitsch considered the tubercles that were only palpated as absent in the study ${ }^{[13]}$ In Gray's Anatomy, ${ }^{[2]}$ this tubercle suggested to be noticed only by palpation. ${ }^{[2]}$ Therefore, we evaluated the visible WTs as apparent and only palpable WTs as nonapparent. This tubercle was observed in all orbits and was not apparent in 11 orbits (25\%) in our study.
Table 2

The clock position and distance of Whitnall's tubercle as with respect to the marginal tubercle.

\begin{tabular}{lcccc} 
& Clock & Number & Percentage (\%) & Distance (mm) \\
\hline \multirow{2}{*}{ Left } & 8 & 13 orbits & 59 & $9.84 \pm 1.51$ \\
\cline { 2 - 5 } & 9 & 9 orbits & 41 & $10.1 \pm 2.37$ \\
\hline \multirow{2}{*}{ Right } & 9 & 9 orbits & 41 & $10.1 \pm 2.37$ \\
\cline { 2 - 5 } & 4 & 15 orbits & 68 & $9.78 \pm 1.46$ \\
\cline { 2 - 5 } & 3 & 6 orbits & 27 & $10.2 \pm 1.27$ \\
\cline { 2 - 5 } & 2 & 1 orbit & 5 & $10.18 \pm 0.08$ \\
\hline
\end{tabular}

\section{Table 3}

The clock position and distance of Whitnall's tubercle with respect to the anterior point of the zygomatic arch.

\begin{tabular}{lcccc} 
& Clock position & Number & Percentage (\%) & Distance (mm) \\
\hline Left & 10 & 22 orbits & 100 & $16.04 \pm 1.69$ \\
\hline \multirow{2}{*}{ Right } & 2 & 20 orbits & 91 & $16.62 \pm 1.76$ \\
\cline { 2 - 5 } & 1 & 2 orbits & 9 & $19.93 \pm 0.56$ \\
\hline
\end{tabular}

Table 4

The kappa values of intraclass and interclass correlation.

\begin{tabular}{lccc} 
& \multicolumn{3}{c}{ Kappa values } \\
\cline { 2 - 4 } Parameters & ACK-NS1 & ACK-NS2 & Intraclass \\
\hline WS1-NS2 \\
\hline WT-marginal tubercle & 0.946 & 0.6 & 0.632 \\
\hline WT-frontozygomatic suture & 0.958 & 0.958 & 1 \\
\hline WT-lateral margin of orbit & 0.789 & 0.788 & 0.998 \\
\hline WT-anterior point of zygomatic arch & 0.954 & 0.979 & 0.969 \\
\hline
\end{tabular}

WT: Whitnall's tubercle.

Previous studies showed that the distances from WT to the frontozygomatic suture and the lateral-inferior margin of the orbit are the most reliable measurements to find out its location. ${ }^{[4,14,23]}$ Moreover, Whitnall ${ }^{[1]}$ first described this 
tubercle to be approximately $11 \mathrm{~mm}$ below the frontozygomatic suture. This distance was $7.4 \pm 2 \mathrm{~mm}$ on the right and $8.3 \pm 1.9 \mathrm{~mm}$ on the left in the study by Fries et al. ${ }^{[8]}$ In our study, the distance between the WT and the frontozygomatic suture was $9.41 \pm 1.46 \mathrm{~mm}$ on the right and $9.91 \pm 1.39 \mathrm{~mm}$ on the left. In the present study and the study by Fries et al., ${ }^{[8]}$ the distance on the left was longer than the right ones. Due to the difference in this distance between studies, we suggested that new parameters were needed to determine the position of this tubercle. So that, we used three new parameters in addition to frontozygomatic suture to define WT in this study: the marginal tubercle, the lateral margin of the orbit and the anterior point of the zygomatic arch. The interclass and intraclass correlations of the WT distances were determined as strong or almost perfect correlations in the present study. By this means, we contributed three new bony landmarks to the literature in addition to the frontozygomatic suture to locate the WT.

The clock position of the WT according to the marginal tubercle had high kappa values of the interclass and intraclass correlations. However, WT was located at 8 and 9 o'clock positions in almost similar percentages to the marginal tubercle on left side. Additionally, it is located at 2, 3 and 4 o'clock positions on right side. These results support orbital asymmetry that is crucial in oculofacial surgery patients. ${ }^{[24,25]}$ For this reason, we suggest that this parameter is not appropriate for clinical use since it may show variations according to sides.

Our study and some recent studies ${ }^{[8,23]}$ have shown that WT is difficult to detect by palpation as it is not always a prominent protrusion. Therefore, the clock position of WT was revealed according to the marginal tubercle and the anterior point of the zygomatic arch in this study. On the Frankfort horizontal plane, the WT was observed on the same plane with the marginal tubercle or slightly below it. In only one case, it was observed above the marginal tubercle on the right side. The WT was found above the anterior point of the zygomatic arch.

The most suitable parameters for determining the position of WT according to the kappa values of intraclass and interclass correlation were the distance of WT to the anterior point of zygomatic arch and the lateral margin of orbit as well as the clock position in between. After determining the location of the WT according to the anterior point of zygomatic arch, the depth of the WT to the lateral margin can easily be determined with the distance between the WT and lateral margin of orbit. These two bony landmarks allow even invisible or non-palpable WTs to be easily detected. In the skulls with apparent WT; both distances and o'clock directions were not different from non-apparent WTs. Thus, it can be predicted as a standard distance and direction before the operation. The WT was about $16 \mathrm{~mm}$ to the anterior point of the zygomatic arch and $10 \mathrm{~mm}$ to the marginal tubercle (Tables 2 and 3). Additionally, there was no significant difference between the directions and the distances. The mean distance did not change in any direction.

\section{Conclusion}

The results of the present study suggests that the marginal tubercle, the lateral margin of the orbit, and the anterior point of the zygomatic arch can be used as reliable bony landmarks in eyelid and orbital surgery to prevent the soft tissue damage associated with WT.

\section{Acknowledgments}

The authors wish to express their gratitude to all those who donated their bodies to medical science.

\section{Conflict of Interest}

The authors certify that they have no conflict of interest and no affiliations or involvement in any organization or entity with any financial or non-financial interest in the subject matter or materials discussed in this manuscript.

\section{Author Contributions}

ACK: project development, data acquisition, photography for figures, writing text, critical revision of the manuscript; NS: project development, data acquisition, critical revision of the manuscript; AU: project development, writing text, critical revision of the manuscript.

\section{Ethics Approval}

All studies carried out in the Department of Anatomy, Ankara University School of Medicine using bone or cadaver specimens are regulated and approved by the Ankara University Faculty of Medicine Clinical Research Ethics Committee Unit.

\section{Funding}

This study did not receive any funding.

\section{References}

1. Whitnall SE. On a tubercle on the malar bone, and on the lateral attachments of the tarsal plates. J Anat Physiol 1911;45:426-32.

2. Mojallal A, Cotofana S. Anatomy of lower eyelid and eyelid-cheek junction. Ann Chir Plast Esthet 2017;62:365-74.

3. Rosenstein T, Talebzadeh N, Pogrel MA. Anatomy of the lateral canthal tendon. Oral Surg Oral Med Oral Pathol Oral Radiol Endod 2000;89:24-8. 
4. Hwang K, Nam YS, Kim DJ, Han SH, Hwang SH. Anatomic study of the lateral palpebral raphe and lateral palpebral ligament. Ann Plast Surg 2009;62:232-6.

5. Kang H, Takahashi Y, Ichinose A, Nakano T, Asamoto K, Ikeda H, Iwaki M, Kazizaki H. Lateral canthal anatomy: a review. Orbit 2012; 31:279-85.

6. Zoumalan CI, Roostaeian J. Simplifying blepharoplasty. Plast Reconstr Surg 2016;137:196e-213e.

7. Whitnall SE. Osteology. In: Whitnall SE, editor. The anatomy of the human orbit and accessory organs of vision. London: Henry Frowde and Hodder \& Stoughton; 1921. p. 13-4.

8. Fries FN, Youssef P, Irwin PA, Tubbs RI, Loukas M, Tubbs RS. Comparing the left and right Whitnall's tubercles and their relation to the frontozygomatic suture: application to symmetry following lateral orbital surgery. Orbit 2016;35:305-8.

9. Didio LJ. The presence of the eminentia orbitalis in the os zygomaticum of Hindu skulls. Anat Rec 1962;142:31-9.

10. Kakizaki H, Zako M, Nakano T, Asamoto K, Miyaishi O, Miyagawa T, Iwaki M. Lateral canthal support system in Japanese. Okajimas Folia Anat Jpn 2006;83:85-90.

11. Ono R. Untersuchungen ueber die Orbita von Japaner. Japanese Journal of Medical Sciences. 1. Anatomy 1928;1:307-8.

12. Kangas T. Das vorkommen des "tuberculum orbitale" in menschlichen Schaedel, insbesondere bei Finnen und Lappen. Duodecim (Helsinki) 1928;1:307-88.

13. Buschkowitsch WJ. Ueber das "tuberculum orbitale" des Jochbeins des Menschen. Anat Anz 1927;63:353-7.

14. Kakizaki H, Malhotra R, Madge SN, Selva D. Lower eyelid anatomy: an update. Ann Plast Surg 2009;63:344-51.

ORCID ID:

A. C. Korkmaz 0000-0002-2217-9326; N. Salman 0000-0003-3927-8010; A. Uz 0000-0002-4005-5466

deomed.
15. Rizvi M, Lypka M, Gaon M, Kovacev T, Eisemann B, Eisemann M. Minimally invasive lateral canthopexy (MILC). J Plast Reconstr Aesthetic Surg 2010;63:1434-6.

16. Hamed-Azzam S, Verity DH, Rose GE. Lateral canthotomy orbitotomy: a rapid approach to the orbit. Eye 2018;32:333-7.

17. Moe KS, Jothi S, Stern R, Gassner HG. Lateral retrocanthal orbitotomy. Arch Facial Plast Surg 2007;9:419-26.

18. Pascali M, Avantaggiato A, Brinci L, Cervelli V, Carinci F. Lateral canthal support in prevention of lower eyelid malpositioning in blepharoplasty: the tarsal sling. J Craniofac Surg 2015;26:e339-e342.

19. Ousterhout DK, Weil RB. The role of the lateral canthal tendon in lower eyelid laxity. Plast Reconstr Surg 1982;69:620-2.

20. Sukhija J, Singh M, Singh U. Profound weakening of the lateral rectus muscle with attachment to lateral canthal tendon for treatment of exotropic Duane syndrome. J AAPOS 2012;16:298-300.

21. Tomita S. On the tuberculum orbitale of the zygomatic bone in the Japanese. Kanazawa Daigaku Igakubu Kaibogaku Kyoshitsu Gyoseki 1935;20:149-54.

22. Gleeson M, Tunstall R. Head and neck: overview and surface anatomy. In: Standring S, editor. Gray's anatomy: the anatomical basis of clinical practice. 41st ed. New York (NY): Elsevier; 2016. p. 410.

23. Anastassov GE, Van Damme PA. Evaluation of the anatomical position of the lateral canthal ligament: clinical implications and guidelines. J Craniofac Surg 1996;7:429-36.

24. Lira J, Langelier N, Lepsch A, Cypen SG, Ranjit-Reeves R, Woodward J. Facial and orbital asymmetry in oculofacial surgery patients. Cutis 2018;101:E22-3.

25. Seiji F, Moreira RS, De Angelis MA, Smith Chairman RL. Orbital asymmetry in development: an anatomical study. Orbit 2009;28:3426.

Correspondence to: Ali Can Korkmaz, MD

Department of Anatomy, Ankara University School of Medicine,

06100, Sihhiye, Ankara, Turkey

Phone: +90554625 4455

e-mail: ackorkmaz@ankara.edu.tr

Conflict of interest statement: No conflicts declared.

This is an open access article distributed under the terms of the Creative Commons Attribution-NonCommercial-NoDerivs 4.0 Unported (CC BY-NCND4.0) Licence (http://creativecommons.org/licenses/by-nc-nd/4.0/) which permits unrestricted noncommercial use, distribution, and reproduction in any medium, provided the original work is properly cited. How to cite this article: Korkmaz AC, Salman N, Uz A. Can Whitnall's tubercle be localized using palpable landmarks around the orbit? Anatomy 2021;15(2):121-126. 